\title{
HSE training matrices templates for grassroots posts in petroleum and petrochemical enterprises
}

\author{
Shao-Lin Qiu ${ }^{1}$ Lai-Bin Zhang $^{1} \cdot$ Mu Liu ${ }^{2}$
}

Handling editor: Jian Shuai

Received: 12 December 2016/Published online: 4 July 2017

(c) The Author(s) 2017. This article is an open access publication

\section{Introduction}

Statistical data in recent years indicate that more than $80 \%$ of incidents and accidents affecting production safety, environment pollution and staff health in petroleum and petrochemical enterprises were caused by illegal operations by grassroots staff with weak HSE awareness and competency (Bush and Ingram 1996; Gitomer 2012; Graduate School of Chinese Academy of Social Sciences 2002; Hu 2012; Jing 2012; Shafiababy et al. 2007; Wang et al. 2008; Wen et al. 2012; Yao 2011). HSE training is an important means to publicize corporate HSE policies and improve employees' HSE knowledge and skills and their abilities in job-related risk identification and control. It is also an integral part of HSE management system and a significant measure to ensure job under control, build HSE culture and continuously improve HSE performance. HSE training for grassroots posts in domestic and foreign petroleum and petrochemical industries mainly has the following four problems: (1) Training content and post demands are not consistent; (2) Training methods are simple and boring, making trainees reluctant to accept them; (3) Positive initiatives for attending training are not strong, without direct relation to staff performance assessment; and (4) Responsibilities of training management are not clear, even none is fixed be in charge of training management in some corporation, so it is difficult to implement linear responsibility. However, so far, no training matrices based on HSE technical requirements of grassroots posts are available in China to specific professional classifications (He 2013; Kernberg 2014; Li 2010; Shevchenko and Kudryavtsev 2012; Weldy et al. 2014; Yao et al. 2011, 2012; Zhang et al. 2016). Since 2007, Chinese oil enterprises began to introduce and explore HSE training matrices management tools, promote HSE training in grassroots units with HSE training matrices as 
the basic carrier and implement "training-on-demand" models to meet job HSE needs (Carr et al. 2000; Finke 2004; Graff and Karsten 2012; Yang et al. 2013). Through effective identification, HSE training matrices can be an effective tool to link HSE training needs and posts and acquire clear instructions on training contents, grasp level, training frequency, etc. (Ahmed and Kolachi 2013; Falkenstein et al, 2016; Puhakainen and Siponen 2010; Yan 2011; Zia et al. 2014). It spells out HSE training requirements in an adequate, vivid, clear and concise manner. However, more applications of HSE training matrices demonstrate deficiencies such as unreasonable design, inaccurate identification of training need and lack of consistency of posts with competence, which restricts the role of HSE training matrices (Hogan et al 2014). Facing the fact that training status is not completely based on real needs of enterprises, it is necessary to research and develop HSE training matrices templates which should be operative, general and suitable for the competency and requirements of grassroots posts and bring a positive effect on the application of HSE training matrices. This paper studies HSE training matrices templates based on technical requirements and following the professional classification of grassroots posts and designs training content, period and methods. Using these templates, hierarchical responsibilities could be implemented and training requirements and technical support measures are defined. Applications of these templates have proved that they can effectively solve training problems of grassroots posts and significantly improve training performance.

\section{Technical requirements for template development}

Application of HSE training matrices to strengthen HSE training for grassroots posts is very different in training mode, form design, requirement analysis and application effect in Chinese oil enterprises. To identify basic training requirements and develop general HSE training matrices templates for key posts in different disciplines (MacDuffie 2007; Montreuil 1996; Nor 2009; Glushenkov 2009; Shadlovskiy and Kovaliov 2013; Shafiabady et al. 2007), the following requirements should be considered:

\subsection{Scope}

HSE training matrices templates for grassroots posts should cover primary business activities in petroleum and petrochemical enterprises, such as exploration and development, refining and petrochemistry, marketing, natural gas and pipelines, engineering technology, surface construction and equipment manufacturing. The specific HSE training matrices template for every business type should cover primary jobs, such as oil production, oil gathering and transportation, refining, petrochemistry, gas stations, oil storage, drilling, downhole operations, geophysical exploration, well logging, surface construction and equipment manufacturing.

\subsection{Operability}

HSE training matrices templates for grassroots posts shall have adequate operability. They should be specific to target posts and specify procedures required for every workplace. Training content should be detailed down to the smallest unit of an operation.

\subsection{Generality}

The development process of HSE training matrices templates for grassroots posts should be standardized by defining business types, breaking down operation, minimizing operating unit and specifying training period, form, trainer and mastery of training content, etc.

\subsection{Suitability}

HSE training matrices templates for grassroots posts should include necessary training content for meeting specific job competency, design appropriate training methods and provide training courses and training materials consistent with grassroots posts. After being trained, all trainees should grasp job skills, understand and be able to control job risks.

\section{Process and technical methods of template development}

After analyzing the HSE training performance in petroleum and petrochemical enterprises, and combing the technical requirements for developing HSE training matrices, the following development process of HSE training matrices for grassroots units was proposed (Fig. 1).

\subsection{Technical preparation}

These data should be prepared as the base for HSE training matrices development, including applicable laws and regulations for related disciplines, grassroots posts, job descriptions and responsibilities, staff structure, available equipment and facilities, processes, procedures.

\subsection{Division of management units}

Aiming at production and management characteristics, job management units should be divided in consideration of related equipment and facilities, processes and (or) 


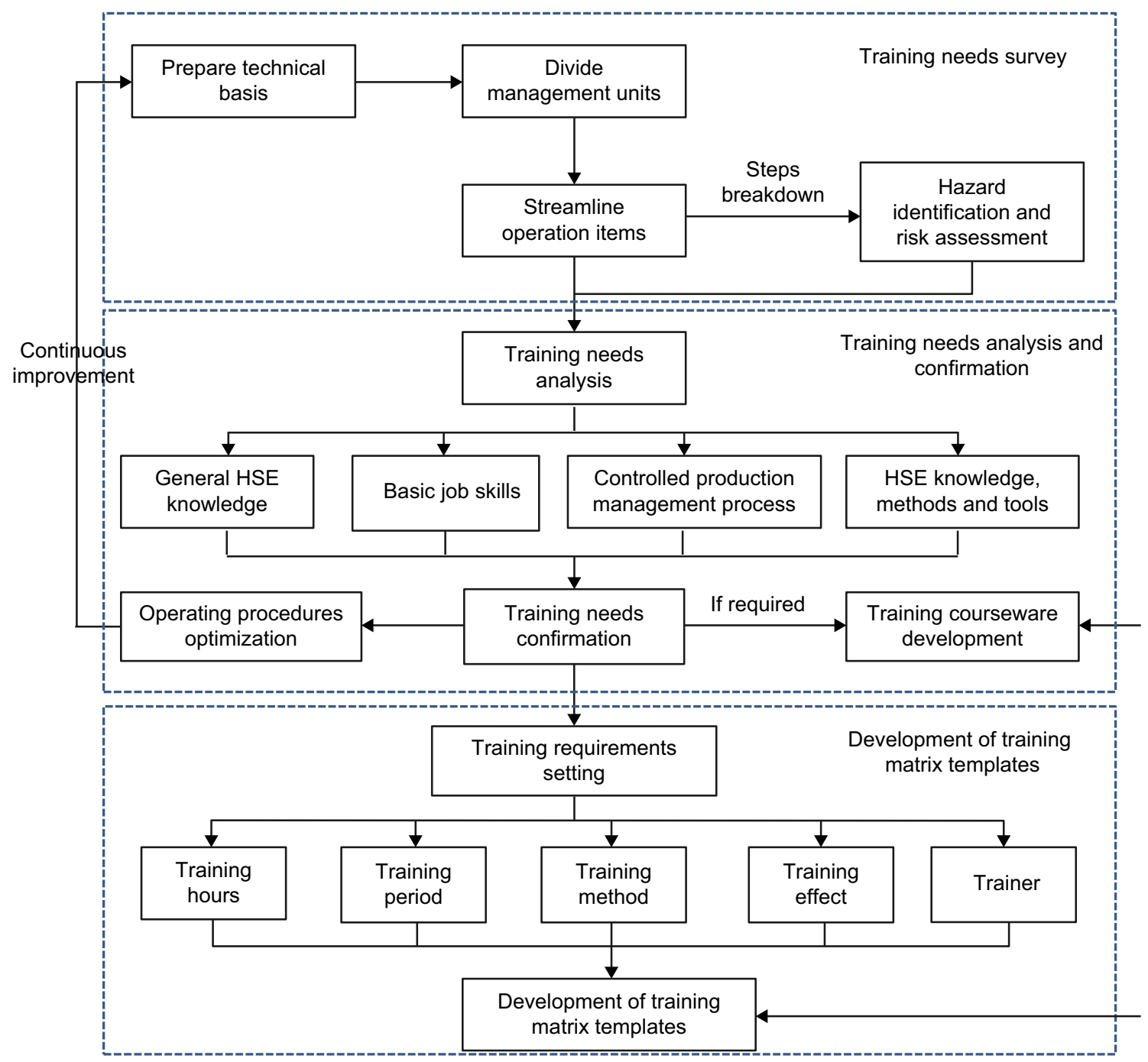

Fig. 1 Development process of HSE training matrices for grassroots units

worksites. For example, oil production activity can be divided into 30 management units in accordance with specific scope of work, job description, workflow, equipment and facilities. Table 1 shows the management unit list.

\subsection{Analysis of operations}

To meet the requirements for keeping every operation relatively independent and complete, operational risks can be identified and control measures can be implemented, and management units should be detailed to the most basic activities. In Table 2, 30 management units in oil production can be broken down into 245 activities.

\subsection{Hazard identification and risk assessment}

For each activity, it is recommended to break down operating procedures or how to dismantle key components of equipment and facilities, conduct hazard identification and risk assessment and develop risk control measures using the job safety analysis (JSA) method, to ensure that the whole process risk management, risk control and emergency response measures are brought into the training needs, laying the foundation for job training matrices application.

\subsection{Training requirement analysis}

According to job responsibilities, operating procedures, risk control and emergency response measures, job-related training requirements are analyzed and determined. Training requirements mainly involve the following four aspects.

\subsubsection{General HSE knowledge}

The general part of HSE training matrices, i.e., general HSE knowledge closely related to staff's activities, daily 
Table 1 Job management unit list of oil production

\begin{tabular}{|c|c|c|c|}
\hline $\mathrm{S} / \mathrm{N}$ & Management unit & $\mathrm{S} / \mathrm{N}$ & Management unit \\
\hline 1 & $\begin{array}{l}\text { Pumping unit installation, uninstallation, transportation, operation, } \\
\text { monitoring, adjustment and maintenance }\end{array}$ & 16 & Water buffer tank operation and maintenance \\
\hline 2 & Screw pump operation, adjustment and maintenance & 17 & Water tank maintenance \\
\hline 3 & Oil well operation, monitoring and maintenance & 18 & $\begin{array}{l}\text { Centrifugal pump installation, operation and } \\
\text { maintenance }\end{array}$ \\
\hline 4 & Christmas tree maintenance & 19 & $\begin{array}{l}\text { Processes in oil gathering and transportation room, } \\
\text { and accessories maintenance }\end{array}$ \\
\hline 5 & Well test & 20 & $\begin{array}{l}\text { Operation and maintenance of gas /oil vacuum/phase } \\
\text { change furnace }\end{array}$ \\
\hline 6 & Metering separator operation, monitoring and maintenance & 21 & $\begin{array}{l}\text { Processes in furnace operating room and accessories } \\
\text { maintenance }\end{array}$ \\
\hline 7 & Maintenance of processes and fittings in the production allocation room & 22 & Pump operation and maintenance in deep water well \\
\hline 8 & High-pressure injection pump (piston pump) operation and maintenance & 23 & Test and analysis of produced oil \\
\hline 9 & Injection well operation, monitoring and maintenance & 24 & Electrical equipment and facilities maintenance \\
\hline 10 & Maintenance of processes and fittings in the water distribution room & 25 & $\begin{array}{l}\text { Maintenance equipment inspection, operation and } \\
\text { maintenance }\end{array}$ \\
\hline 11 & Two-phase separator operation and maintenance & 26 & Inspection tour \\
\hline 12 & Three-phase separator operation and maintenance & 27 & Upgrading and fixing of oil/gas/water pipelines \\
\hline 13 & Oil skimmer operation and maintenance & 28 & General accessories maintenance \\
\hline 14 & Dryer operation and maintenance & 29 & $\begin{array}{l}\text { Single-well tank installation, operation, maintenance } \\
\text { and adjustment }\end{array}$ \\
\hline 15 & Air purifier operation and maintenance & 30 & Logistics support and management \\
\hline
\end{tabular}

Table 2 List of basic activities in oil production (partial)

\begin{tabular}{llll}
\hline S/N & Basic activity & S/N & Basic activity \\
\hline 2.1 & Installation of pumping unit & 2.3 & Oil well operation, monitoring and maintenance \\
2.1 .1 & Overall installation of pumping unit & 2.3 .1 & Measurement of tubing pressure \\
2.1 .2 & Assembly and disassembly of pumping unit & 2.3 .2 & Measurement of casing pressure \\
$\ldots$ & $\ldots$ & 2.3 .3 & Well sampling \\
2.2 & Screw pump operation, adjustment and maintenance & 2.3 .4 & Adjustment of collision avoidance distance for pumping well \\
2.2 .1 & Screw pump start-up & $\ldots$ & $\ldots$ \\
2.2 .2 & Screw pump shutdown & 2.4 & Well test \\
$\ldots$ & $\ldots$ & $\ldots$ & $\ldots$ \\
\hline
\end{tabular}

life and jobs and that should be mastered, includes jobrelated laws and regulations, job HSE risks, equipment and material used, emergency response and prevention measures and typical incidents as shown in Table 3.

\subsubsection{Basic job skills}

Professional skills of HSE training matrices refer to the training contents set specifically to a job based on job requirement analysis. It mainly includes training in operation procedures, such as technical skills for equipment management, operational activities and processes (Table 4). Through training, employees can grasp job-related skills, hazard identification and risk control methods, emergency response procedures, etc.

\subsubsection{Controlled production management process}

According to the training requirements set for controlled production management, all employees should understand or master related controlled management requirements applicable to their jobs and apply them to HSE management, which mainly includes related controlled management activities and contents, e.g., permit-to-work management, process and equipment management, management of change and contractor management.

\subsubsection{HSE knowledge, methods and tools}

According to the training requirements set for an HSE management system, all employees are required to 
Table 3 JSA before well shut-in (example)

Unit Unit name All hazards and risks and the corresponding measures to eliminate, mitigate and control these hazards and risks have been discussed, understood and confirmed by all personnel involved in this job, including emergency response measures, so the work can be started.

Duty holder

Brief description of the task

\begin{tabular}{|c|c|c|c|}
\hline Procedure & Hazard(s) & Risk control measure(s) & $\begin{array}{l}\text { Emergency response } \\
\text { measure }(\mathrm{s})\end{array}$ \\
\hline $\begin{array}{l}\text { 1. Check work preparation and } \\
\text { recorded data }\end{array}$ & 1. Mechanical injury & $\begin{array}{l}\text { 1. Wear necessary personal } \\
\text { protective equipment (PPE) }\end{array}$ & $\begin{array}{l}\text { 1. First-aid kit available on the } \\
\text { site and send to the medical } \\
\text { clinic in the work area in } \\
\text { serious cases }\end{array}$ \\
\hline $\begin{array}{l}\text { 2. Notify central control room } \\
\text { (CCR) and close secondary } \\
\text { nozzles and then primary } \\
\text { nozzles on site }\end{array}$ & 1. Mechanical injury & $\begin{array}{l}\text { 1. Wear necessary PPE and } \\
\text { stand aside while operating } \\
\text { valves }\end{array}$ & $\begin{array}{l}\text { 1. First-aid kit available on the } \\
\text { site and send to the medical } \\
\text { clinic in the work area in } \\
\text { serious cases }\end{array}$ \\
\hline 3. Remote/on-site well shut-in & $\begin{array}{l}\text { 1. Suffocation injury: Entry } \\
\text { into cellar valve chamber } \\
\text { may cause suffocation due to } \\
\text { gas leakage } \\
\text { 2. Mechanical injury }\end{array}$ & $\begin{array}{l}\text { 1. Entry into the valve chamber } \\
\text { shall comply with the } \\
\text { Regulations on Entry into } \\
\text { Cellar Valve Chamber by } \\
\text { Gas Production Crew } \\
\text { 2. Wear necessary PPE; stand } \\
\text { aside while operating valves; } \\
\text { do not stand near Christmas } \\
\text { tree and pipelines; do not } \\
\text { open the back door of the } \\
\text { hydraulic control cabinet }\end{array}$ & $\begin{array}{l}\text { 1. Once a suffocation injury } \\
\text { occurs, the monitoring } \\
\text { personnel shall immediately } \\
\text { wear positive pressure } \\
\text { breathing apparatus and } \\
\text { enter the valve chamber to } \\
\text { move the injured out and } \\
\text { give first-aid treatment. } \\
\text { 2. Once a mechanical injury } \\
\text { occurs, immediately give } \\
\text { first-aid treatment, and then } \\
\text { send to the medical clinic in } \\
\text { the work area }\end{array}$ \\
\hline $\begin{array}{l}\text { 4. Long shut-in: Close all } \\
\text { nozzles, hydraulic wing } \\
\text { valves, manual wing valves, } \\
\text { hydraulic master valves, } \\
\text { manual master valves and } \\
\text { downhole safety valves, and } \\
\text { decide the branch pressure } \\
\text { according to real situations; } \\
\text { report well shut-in to CCR } \\
\text { and record valve switch } \\
\text { status }\end{array}$ & 1. Mechanical injury & $\begin{array}{l}\text { 1. Wear necessary PPE and } \\
\text { stand aside while operating } \\
\text { valves }\end{array}$ & $\begin{array}{l}\text { 1. First-aid kit available on the } \\
\text { site and send to the medical } \\
\text { clinic in the work area in } \\
\text { serious cases }\end{array}$ \\
\hline
\end{tabular}

understand or master related national, industrial and corporate HSE requirements which mainly include basic HSE knowledge, tools and methods, e.g., JSA, job cycle analysis (JCA), safety observation and communication, and safety experience sharing. Besides, all employees should be able to apply HSE management methods and tools to routine HSE work using with their HSE knowledge.

\subsection{Training requirements and training matrices development}

Training requirements set up training goals and performance indicators. Four points of every post, training requirement, namely duration, frequency and trainers (Table 5), should be defined and specific HSE training matrices should be established based on job responsibilities, training requirement, courses and trainees as shown in Table 6.

\subsection{Training outline (if required)}

Training outlines should be consistent, relatively complete, simple and concise (Table 2). Materials like video, audio and photographs can be used to illustrate HSE principles and practices in order to attract trainees to interactive participation.

\subsection{Optimization of operating procedures}

Training contents should be determined based on operating procedures. It is recommended to use tools and methods such as JCA and JSA to analyze the effectiveness of job- 


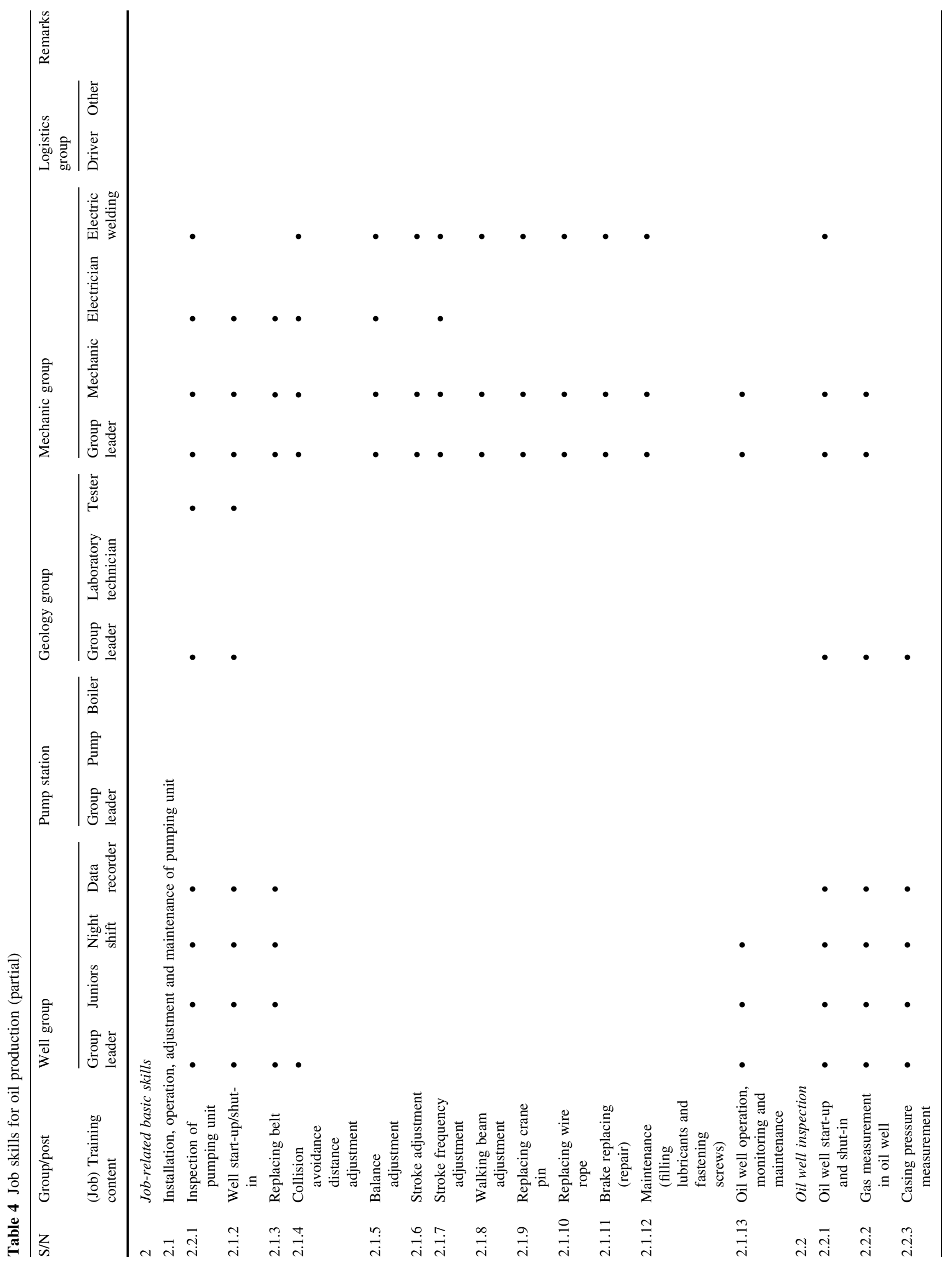




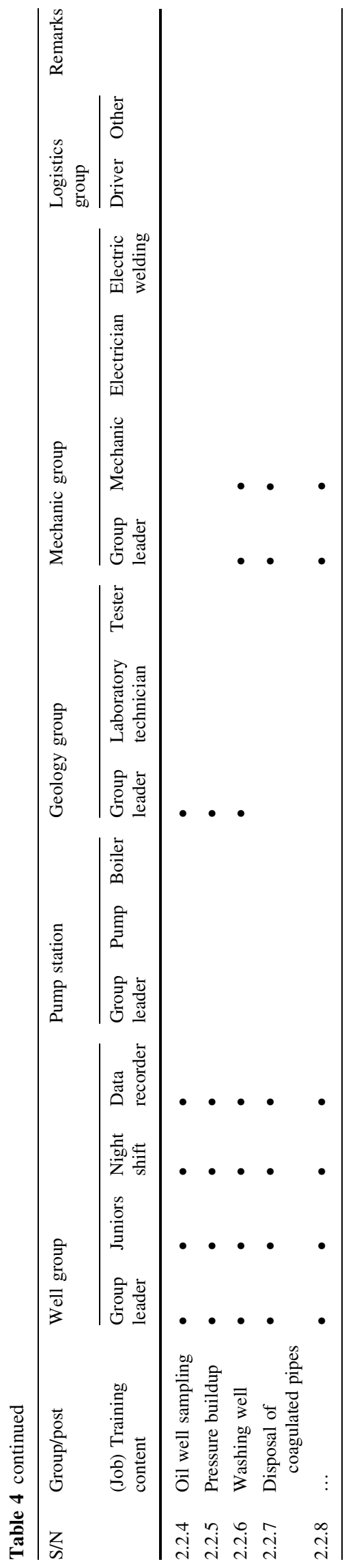

related procedures which should be revised when necessary. To keep continuous improvement in training work, training matrices should be improved in accordance with the revision of operating procedures.

\section{Application and improvement in HSE training matrices templates}

\subsection{Results of templates development}

Using the technical methods above, 239 grassroots posts in 22 primary disciplines in petroleum and petrochemical industries (based on an investigation of 12 petroleum and petrochemical enterprises) were studied, and based on which 983 management units covering 4566 activities were proposed and defined, and accordingly, 239 HSE training matrices and 1726 training outlines were established.

\subsection{Templates application}

Application of these HSE training matrices templates was used in an oil field company and obtained the following results:

1. These HSE training matrices templates for grassroots posts can standardize job requirements and competency building, make HSE training for grassroots posts standard, systematic and scientific, enhance on-site risk management and control levels, improve job operating procedures and enlarge the application of HSE management tools and methods.

2. These HSE training matrices embody job-related basic HSE training requirements. Training is given by line managers. Training contents focus on safety and environmental risks on specific work and are concise, understandable, operable and interesting.

3. With appropriate incentive mechanism, all employees at all levels are active to pursue their initiatives and participate in development and revision of operating procedures and training matrices. This practice is supported and understood by all employees.

4. Dynamic management and sustainable improvement in the HSE training matrices make them adapt to changing management structure processes.

\subsection{Future improvement}

Analysis of the actual applications of these HSE training matrices templates indicates that future improvement can be carried out in the following aspects: 
Table 5 Typical HSE training matrices for oil production juniors (partial)

\begin{tabular}{|c|c|c|c|c|c|c|}
\hline $\mathrm{S} / \mathrm{N}$ & Training description & $\begin{array}{l}\text { Duration } \\
\text { (hours) }\end{array}$ & Frequency & Method & Requirement & Trainer \\
\hline 1 & General HSE knowledge & & & & & \\
\hline 1.1 & HSE responsibilities, rights and obligations & 0.50 & $\begin{array}{l}\text { Every } \\
\quad 1 \text { year }\end{array}$ & $\begin{array}{l}\text { Lecturing or } \\
\text { meeting }\end{array}$ & Mastery & $\begin{array}{l}\text { Group leader/HSE } \\
\text { officer }\end{array}$ \\
\hline 1.2 & Crude oil HSE knowledge & 0.25 & $\begin{array}{l}\text { Every } \\
3 \text { years }\end{array}$ & Lecturing & Mastery & $\begin{array}{l}\text { Group leader/HSE } \\
\text { officer }\end{array}$ \\
\hline 1.3 & Gas HSE knowledge & 0.25 & $\begin{array}{l}\text { Every } \\
3 \text { years }\end{array}$ & Lecturing & Mastery & $\begin{array}{l}\text { Group leader/HSE } \\
\text { officer }\end{array}$ \\
\hline 1.4 & Emergency escape knowledge & 0.50 & $\begin{array}{l}\text { Every } \\
\quad 1 \text { year }\end{array}$ & $\begin{array}{l}\text { Lecturing }+ \\
\quad \text { field }\end{array}$ & Mastery & $\begin{array}{l}\text { Group leader/HSE } \\
\text { officer }\end{array}$ \\
\hline 1.5 & $\cdots$ & $\cdots$ & $\cdots$ & $\cdots$ & $\cdots$ & $\cdots$ \\
\hline 2 & Basic job skills & & & & & \\
\hline 2.1 & $\begin{array}{l}\text { Operation, maintenance and adjustment of } \\
\text { pumping unit }\end{array}$ & & & & & \\
\hline 2.1 .1 & Start-up and shutdown of pumping unit & 0.50 & 3 years & $\begin{array}{l}\text { Lecturing }+ \\
\quad \text { field }\end{array}$ & Mastery & $\begin{array}{l}\text { Group leader/HSE } \\
\text { officer }\end{array}$ \\
\hline 2.1 .2 & Replacing the belt of a pumping unit & 0.5 & 3 years & $\begin{array}{l}\text { Lecturing }+ \\
\quad \text { field }\end{array}$ & Mastery & $\begin{array}{l}\text { Group leader/HSE } \\
\text { officer }\end{array}$ \\
\hline 2.1 .3 & $\begin{array}{l}\text { Pumping unit maintenance (fill lubricants and } \\
\text { fasten screws) }\end{array}$ & 0.50 & 3 years & $\begin{array}{l}\text { Lecturing }+ \\
\quad \text { field }\end{array}$ & Mastery & $\begin{array}{l}\text { Group leader/HSE } \\
\text { officer }\end{array}$ \\
\hline 2.1 .4 & $\cdots$ & $\cdots$ & $\cdots$ & $\cdots$ & $\cdots$ & $\cdots$ \\
\hline 3 & Controlled management process & & & & & \\
\hline 3.1 & Permit to work & 0.50 & 3 years & $\begin{array}{l}\text { Lecturing }+ \\
\quad \text { field }\end{array}$ & Understanding & $\begin{array}{l}\text { Squad leader or HSE } \\
\text { officer }\end{array}$ \\
\hline 3.2 & Lock out and tag out & 0.50 & 3 years & $\begin{array}{l}\text { Lecturing }+ \\
\quad \text { field }\end{array}$ & Mastery & $\begin{array}{l}\text { Squad leader or HSE } \\
\text { officer }\end{array}$ \\
\hline 3.3 & $\cdots$ & $\cdots$ & $\cdots$ & $\cdots$ & $\cdots$ & $\cdots$ \\
\hline 4 & HSE knowledge, methods and tools & & & & & \\
\hline 4.1 & JSA & 0.25 & 3 years & $\begin{array}{l}\text { Lecturing or } \\
\text { meeting }\end{array}$ & Understanding & $\begin{array}{l}\text { Squad leader or HSE } \\
\text { officer }\end{array}$ \\
\hline 4.2 & Site management & 0.50 & 3 years & $\begin{array}{l}\text { Lecturing or } \\
\text { meeting }\end{array}$ & Mastery & $\begin{array}{l}\text { Squad leader or HSE } \\
\text { officer }\end{array}$ \\
\hline 4.3 & $\cdots$ & $\cdots$ & $\cdots$ & $\cdots$ & $\cdots$ & $\cdots$ \\
\hline
\end{tabular}

Table 6 Training outlines

\begin{tabular}{|c|c|c|}
\hline Outlines for basic job skills & $\begin{array}{l}\text { Outlines for controlled management } \\
\text { procedure }\end{array}$ & $\begin{array}{l}\text { Outlines for HSE knowledge, methods and } \\
\text { tools }\end{array}$ \\
\hline 1. Pre-job preparation & 1. Basic definitions & 1. Basic definitions and explanations \\
\hline $\begin{array}{l}\text { 2. Procedures (hazard identification and risk } \\
\text { control) }\end{array}$ & $\begin{array}{l}\text { 2. Management process and requirements } \\
\text { 3. Typical cases }\end{array}$ & $\begin{array}{l}\text { 2. Why promote? } \\
\text { 3. How to implement effectively? }\end{array}$ \\
\hline $\begin{array}{l}\text { 3. Emergency response and accident prevention } \\
\text { (cases) }\end{array}$ & 4. Cautions & 4. Cautions and summary \\
\hline
\end{tabular}

1. The department in charge of training should fully play a leading role in strengthening the compliance with the enterprise's overall human resource management policies, unifying the management of output interfaces and effectively integrating various resources.
2. As different enterprises have different organizations, production techniques, equipment, facilities, allocations of posts and responsibilities, businesses and activities, they have different requirements for jobrelated HSE competency. The generality of the HSE 
training matrices templates may not meet specific requirements. Therefore, as equipment, technologies and processes upgrade, the templates should be improved and revised accordingly.

3. Less professional technologies and human resources for developing exclusive training materials result in repeated development of general materials in enterprises. To increase the utilization of training resources, it is necessary to establish resource sharing and incentives and performance assessment policies.

\section{Conclusions}

1. HSE training matrices templates were developed for 239 grassroots posts in 22 primary disciplines of petroleum and petrochemical industries. The development of these HSE training matrices templates for grassroots posts complies with the training requirement of HSE management and is a re-innovation in HSE training for Chinese oil enterprises.

2. The application of these HSE training matrices templates for grassroots posts strengthens risk management and control, optimizes operating procedures, promotes the application of HSE systems and tools, highlights HSE responsibilities and improves training management mechanisms in grassroots units.

3. Future work should focus on dynamic and sustainable improvement in HSE training matrices templates, development of training resources sharing platforms and promotion and application technologies of training matrices, to meet the ever-developing enterprises, processes and technologies, equipment and facilities, laws, regulations, standards and specifications, and stringent job-related risks and control requirements.

Open Access This article is distributed under the terms of the Creative Commons Attribution 4.0 International License (http://crea tivecommons.org/licenses/by/4.0/), which permits unrestricted use, distribution, and reproduction in any medium, provided you give appropriate credit to the original author(s) and the source, provide a link to the Creative Commons license, and indicate if changes were made.

\section{References}

Ahmed I, Kolachi NA. Employee payroll and training budget: Case study of a non-teaching healthcare organization. J Bus Econ Res. 2013;11(5):229. doi:10.19030/jber.v11i5.7838.

Bush VD, Ingram T. Adapting to diverse customers: a training matrices for international marketers. Ind Market Manag. 1996;25(5):373-83. doi:10.1016/0019-8501(96)00039-9.
Carr JE, Nicolson AC, Higbee TS. Evaluation of a brief multiplestimulus preference assessment in a naturalistic context. J Appl Behav Anal. 2000;33:353-7. doi:10.1901/jaba.2000.33-353.

Falkenstein M, Gajewski PD, Michael F, Patrick DG. Changes of electrical brain activity after cognitive training in old adults and older industrial workers. In: Strobach T, Karbac J, editors. Cognitive training. Berlin: Springer International Publishing; 2016. p. 177-86. doi:10.1007/978-3-319-42662-4_17.

Finke M. GMP aspects in practice: topical items concerning GMP regulations-training demands on staff in GMP conforming areas-Establishing a training system. Die Pharmazeutische Industrie. 2004;66(6):765-8.

Gitomer J. The hard side of training and the soft side of learning. Enterp Salt Lake City. 2012;41(47):8.

Glushenkov DA. Applying systems of video conference communication based on a software endec in the training of state employees. Sci Techn Inf Process. 2009;36(2):90-1. doi:10.3103/S0147 68820902004X

Graduate School of Chinese Academy of Social Sciences. Harvard model training management, vol. 1-3. Beijing: People's Daily Press; 2002. p. 1-27 (in Chinese).

Graff RB, Karsten AM. Evaluation of a self-instruction package for conducting stimulus preference assessments. J Appl Behav Anal. 2012;45(1):69-82. doi:10.1901/jaba.2012.45-69.

$\mathrm{He} \mathrm{H}$. Tailored training based on unique post needs: brief analysis on the application of HSE training matrices in the Tahe Oilfield. China Sci Technol Inf. 2013;17:124-5 (in Chinese).

Hogan DA, Greiner BA, O'Sullivan L. The effect of manual handling training on achieving training transfer, employee's behavior change and subsequent reduction of work-related musculoskeletal disorders: a systematic review. Ergonomics. 2014;57(1): 93-107. doi:10.1080/00140139.2013.862307.

$\mathrm{Hu}$ YT. Training matrices management: an effective model for improving the effectiveness of training. J Beijing Pet Manag Train Inst. 2012;5:72 (in Chinese).

Jing WR. HSE-based workover job skill requirements and training design of an oil and gas field. Master Thesis Jilin University; 2012. p. 15 (in Chinese).

Kernberg OF. The twilight of the training analysis system. Psychoanal Rev. 2014;101(101):151-74. doi:10.1521/prev.2014.101.2.151.

Li J. Application of training matrices in HSE management of pipeline construction contractor. Health Saf Environ. 2010;10(7):10-2 (in Chinese).

MacDuffie JP. Human resource bundles and manufacturing performance: organizational logic and flexible production systems in the world auto-industry. Ind Lab Relat Rev. 2007;48(2): 197-221. doi: $10.2307 / 2524483$.

Montreuil S. Ergonomics training for managers, employees and designers involved in the design and organization of work systems. Saf Sci. 1996;23(2):97-106. doi:10.1016/0925-7535 (96)00035-5.

Nor NM. A requirements model for employees training management system: applying WAE-UML. Information Management and Engineering, 2009. ICIME'09. International Conference on. IEEE, 2009. p. 569-73. 10.1109/ICIME.2009.67.

Puhakainen P, Siponen M. Improving employees' compliance through information systems security training: an action research study. MIS Q. 2010;34(4):757-78.

Shadlovskiy EL, Kovaliov YT. Cognitive training in older employees: a comparison between office and industrial workers. J Psychophysiol. 2013;27:69. doi:10.1027/0269-8803/a000095.

Shafiabady N, Teshnehlab M, Shooredeli MA. Training matrices parameters by particle swarm optimization using a fuzzy neural network for identification. In: International conference on intelligent \& advanced systems, 2007. p. 188-93. doi:10.1109/ ICIAS.2007.4658372. 
Shevchenko DI, Kudryavtsev AA. The "Oil and Gas Enterprise" integrated training system. Oil Gas Eur Mag. 2012;38(4):218-9.

Wang XX, Su GS, Zhang Y. Inspiration on HSE education and training of petrochemical enterprises. Saf Health Environ. 2008;8(1):14-5 (in Chinese).

Weldy CR, Rapp JT, Capocasa K. Training staff to implement brief stimulus preference assessments. J Appl Behav Anal. 2014; 47(1):214-8. doi:10.1002/jaba.98.

Wen ZG, Dong PJ, Liu B. Matrices-type HSE training for oil depot employees. Saf Health Environ. 2012;12(9):52-3 (in Chinese).

Yan XY. Instructional system design in employee training in the industrial area: take research on the "Blue-Collar Talent" project in Xiasha Economic and Technological Development Zone of Hangzhou as the example. Appl Mech Mater. 2011;121-126: 912-7. doi:10.4028/www.scientific.net/AMM.121-126.912.

Yang DL, Liu SY, Yang B, et al. Research the training system of the oil field staff simulation based on virtual reality technology. Adv
Mater Res. 2013;807-809:2863-7. doi:10.4028/www.scientific. net/AMR.807-809.2863.

Yao GY. HSE training practice and work direction in petrochemical enterprises. Safety, Health and Environment. 2011;11(2):11 (in Chinese).

Yao GY, Liu ZH, Zhao LQ. Establishment of HSE training matrices in petrochemical enterprises. Saf Environ Eng. 2011;18(5):74-7 (in Chinese).

Yao G, Wang J, Wu B. The establishment of HSE training matrices for HSE professional management staffs in refining-chemical enterprises. Technol Superv Pet Ind. 2012;1:24-9 (in Chinese).

Zhang Q, Zhao G, Wang L, et al. Application of training matrices in the top level design of enterprise HSE Training. Environ Prot Oil Gas Fields. 2016;26(3):55-8 (in Chinese).

Zia H, Ishaq HM, Zahir S, et al. To investigate the impact of training, employee empowerment and organizational climate on job performance. Res J Appl Sci Eng Technol. 2014;7(22):4832-7. doi:10.19026/rjaset.7.872. 